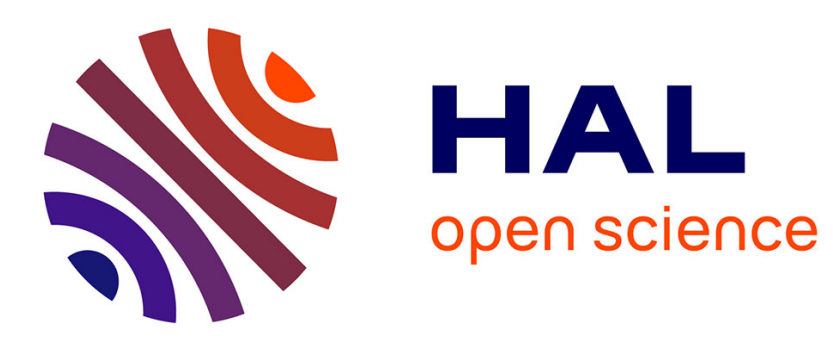

\title{
Full Disclosure in Decentralized Organizations
}

Jeanne Hagenbach, Frédéric Koessler

\section{To cite this version:}

Jeanne Hagenbach, Frédéric Koessler. Full Disclosure in Decentralized Organizations. 2011. halshs00652279

\section{HAL Id: halshs-00652279 \\ https://shs.hal.science/halshs-00652279}

Preprint submitted on 15 Dec 2011

HAL is a multi-disciplinary open access archive for the deposit and dissemination of scientific research documents, whether they are published or not. The documents may come from teaching and research institutions in France or abroad, or from public or private research centers.
L'archive ouverte pluridisciplinaire HAL, est destinée au dépôt et à la diffusion de documents scientifiques de niveau recherche, publiés ou non, émanant des établissements d'enseignement et de recherche français ou étrangers, des laboratoires publics ou privés. 


\section{PARISSCHOQL OF ECONOMICS}

WORKING PAPER N² 2011 - 41

Full Disclosure in Decentralized Organizations

Jeanne Hagenbach

Frederic Koessler

JEL Codes: C72; D82

Keywords: Certifiable types ; Coordination, information disclosure ; Multidivisional organizations

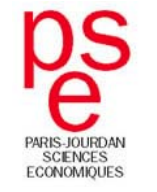




\title{
Full Disclosure in Decentralized Organizations *
}

\author{
Jeanne HagenBACH ${ }^{\dagger} \quad$ Frédéric KOESSLER ${ }^{\ddagger}$
}

December 12, 2011

\begin{abstract}
We characterize sufficient conditions for full and decentralized disclosure of hard information in organizations with asymmetrically informed and self interested agents with quadratic loss functions. Incentive conflicts arise because agents have different (and possibly interdependent) ideal actions and different incentives to coordinate with each others. A fully revealing sequential equilibrium exists in the disclosure game if each player's ideal action is monotonic in types and types are independently distributed, but may fail to exist with non-monotonic ideal actions or correlated types. When biases between players' ideal actions are constant across states, complete information is the Pareto dominant information structure. In that case, there is a fully revealing sequential equilibrium in which informational incentive constraints are satisfied ex-post, so it exists for all possible prior beliefs, even when players' types are correlated. This existence result applies whether information disclosure is private or public, and is extended to partial certifiability of information.
\end{abstract}

KEywords: Certifiable types, coordination, information disclosure, multi-divisional organizations.

JEL Classification: C72; D82.

${ }^{*}$ We thank Yann Bramoullé, Rachel Kranton, Laurent Lamy, Eduardo Perez, and seminar participants at EUI Florence, SFB-TR15 Seminar in Berlin, Stony Brook Conference on Game Theory 2011, and Games Toulouse 2011. The second author thanks the "Agence National de la Recherche" (ANR) for financial support.

${ }^{\dagger}$ École Polytechnique - CNRS. E-mail : jeanne.hagenbach@polytechnique.edu

${ }^{\ddagger}$ Paris School of Economics - CNRS. E-mail : koessler@pse.ens.fr 


\section{Introduction}

We consider organizations whose members want to coordinate the actions they take in a decentralized way, but disagree on the ideal decision to coordinate on. Every agent's ideal decision is assumed to potentially depend on the private information that every other agent has, about the environment of the group for instance. In such contexts, information revelation within the organization entails a strategic aspect as agents may try to influence others' choices by misrepresenting what they know. This paper focuses on the internal communication phase preceding the one in which payoff-relevant decisions are made. We consider costless disclosure of hard (or certifiable) information and investigate players' incentives to reveal completely and voluntarily their information to others.

One example of such an organization is a national association made up of several regional divisions, each taking operating decisions separately. If these decisions are local investments in public facilities for instance, some coordination may be needed to create coherence at the national level. Similarly, in a multidivisional corporation, if each division chooses a kind of product to be locally launched, coordination may be necessary to keep some harmony under a brand name. In each case however, local particularities can be at the origin of disagreements between divisions about the ideal action to coordinate on. At the same time, each division is likely to have some private information which partly describes the overall context in which the whole organization evolves, and therefore affects the agents' ideal actions. The regional state of road safety or the local taste of the customer base give part of the national picture and are examples of such private pieces of information. In this paper, divisions have the opportunity to communicate this private information to each other before acting. We examine the disclosure phase in which players have the option to certify precisely their information, but may want to conceal it or use incomplete and biased statements to influence other players' decisions in their preferred direction.

We use a class of coordination games of asymmetric information to represent the multidivisional organizations described above. This class of games is the object of a recent literature in the economics of networks and organizations (e.g., Morris and Shin, 2002, Angeletos and Pavan, 2007, Calvó-Armengol and Martí, 2007, Alonso, Dessein, and Matouschek, 2008, Hagenbach and Koessler, 2010, Calvo-Armengol, De Martí, and Prat, 2011) ${ }^{1}$, and we depart from existing works in that we comprehend internal communication as strategic disclosure of free but verifiable messages. Each member of our organization has two types of motives, represented by quadratic cost functions trading-off between (i) the adaptation of his decision to an idiosyncratic value or "ideal action" that may depend on his but also on others' private information, and (ii) the coordination of his decision with the others' ones. In such situations, we ask whether it is possible to have full disclosure of information despite the conflict of interests faced by agents regarding their ideal actions.

We first provide sufficient conditions on general Bayesian games for the existence of a fully revealing sequential equilibrium in the disclosure game preceding the action stage. Next, we apply this result to organizations with independent types and ideal actions which are monotone with every private information. For example, when every player's ideal action only depends on his private information, monotonicity is always satisfied. Under the additional assumption that the difference between any pair of players' ideal actions is given by a constant bias across states, full

\footnotetext{
${ }^{1}$ See the next section for a short review of this literature and the differences with our approach.
} 
disclosure induces a Pareto dominant information structure. In that case, we show that informational incentive constraints are also satisfied ex-post, so a fully revealing equilibrium exists for all possible prior beliefs, in particular when players' types are correlated. This existence result applies whether information disclosure is private or public, and is finally extended to partial certifiability of information.

The next section discusses our contribution to the literature on disclosure games and to the literature on organizational economics. Section 3 presents the model and a general preliminary result on the existence of a fully revealing sequential equilibrium in general Bayesian games. Full information disclosure in organizations with independent types is analyzed in Section 4. Section 5 extends our existence result to ex-post incentive compatibility, private disclosure and partial certifiability in the special case of constant biases between players' ideal actions. Section 6 concludes. Some proofs are relegated to the Appendix.

\section{$2 \quad$ Related Literature}

\subsection{Strategic Information Revelation}

Grossman (1981) and Milgrom (1981) consider seller-buyer relationships in which the seller is privately informed about the quality of the product and has an interest in appearing of better quality to the buyer. They show that if it is costless to provide hard evidence about minimal levels of product quality, then there is a unique sequential equilibrium outcome, in which the buyer completely learns product information from the seller. ${ }^{2}$ The proof of this result relies on a straightforward unravelling argument. Uniqueness follows from the fact that if multiple types of the seller pool together, then the highest quality type has an incentive to deviate and disclose his type. Existence is obtained by considering "sceptical" beliefs for the buyer: any partial disclosure of quality is interpreted as coming from the lowest possible quality type of the firm.

Okuno-Fujiwara, Postlewaite, and Suzumura (1990) generalize this unravelling result to a class of $n$-person games (with quadratic utility functions when $n>2$ ) in which players are privately and independently informed, assuming that equilibrium payoffs are unique and monotone in beliefs. When equilibrium payoffs are monotone in beliefs, a fully revealing equilibrium can be constructed as in Grossman (1981) and Milgrom (1981) with sceptical beliefs putting probability one on the lowest or the highest possible type of each sender. A typical example is a linear Cournot game with homogeneous goods and privately known marginal costs, in which each firm's equilibrium payoff decreases when other firms' beliefs about the level of its cost increase. A sceptical belief is therefore simply to put probability one on the highest possible marginal cost compatible with a firm's report. Van Zandt and Vives (2007) prove the existence of a fully revealing equilibrium in a class of Bayesian games with strategic complementarities, without assuming quadratic payoff functions, but assuming as in Okuno-Fujiwara et al. (1990) that types are independently distributed and that each player's utility function is monotone in the actions of the other players.

\footnotetext{
${ }^{2}$ This result does not always apply when products cannot be ordered in terms of quality, i.e., if different consumer types have different tastes for product characteristics (see, e.g., Anderson and Renault, 2006, Johnson and Myatt, 2006, Koessler and Renault, 2011, and Sun, 2011) or if there is competition between several sellers (see, e.g., Board, 2009).
} 
The assumption of monotone payoffs with respect to others' actions and beliefs is not satisfied in strategic situations in which players' preference over others' actions depend on the state of the world. For example, in the class of coordination games we are studying, when a player's ideal action is relatively high (low, respectively) he prefers others' actions to increase (decrease, respectively). Seidmann and Winter (1997), Giovannoni and Seidmann (2007) and Mathis (2008) have studied disclosure in games with such state-dependent preferences over others' actions. As in Grossman (1981) and Milgrom (1981) they consider sender-receiver games with a single informed player (the sender) and a single decisionmaker (the receiver). A simple application of their result on the existence of a fully revealing equilibrium is the class of games studied by Crawford and Sobel (1982) where preferences are single-peaked and players' ideal actions are increasing in the sender's type. Interestingly, contrary to the framework of Crawford and Sobel (1982), their model also allow for the bias between the sender and the receiver to change sign. ${ }^{3}$ In that situation, as it is also the case in our model, sceptical beliefs off the equilibrium path are more sophisticated because they do not necessarily put probability one on the highest or lowest possible type compatible with a sender's report. The proof of the existence of a fully revealing equilibrium in such a situation relies on the existence of a "worst-case type" for every possible subset of types of the sender (i.e., a type that no type in that subset wants to imitate) without necessarily characterizing explicitly what this worst-case type is.

Our first proposition, applied to coordination games assuming independent types, uses a generalization of the argument of Seidmann and Winter (1997) to prove that a "worst-case type" always exists. It is based on our general result (Lemma 1) using the same "no reciprocal imitation" condition as Seidmann and Winter, ${ }^{4}$ and an additional condition that we call "partially transitive imitation". This second condition is not required in Seidmann and Winter where the sender's preference over the receiver's belief is singled-peaked, an assumption that may not be satisfied in our model when there are more than two players. The proof of our second proposition, assuming constant biases, is more constructive and a worst-case type can be explicitly characterized as a function of the sender's identity, the profile of players' biases, and the degrees of strategic complementarities between players' actions. This allows to easily relax the assumption that every single type is certifiable, and also allows to show that informational incentive constraints are valid ex-post, once players have learned others' types. Hence, a fully revealing equilibrium exists whatever players' beliefs, even when players' types are correlated. We also extend this result to private information revelation, which has not been considered in Okuno-Fujiwara et al. (1990) and Van Zandt and Vives $(2007) .^{5}$

\subsection{Communication in Organizations}

Our class of coordination games with incomplete information has received much interest in the economic literature on organizations, but only recently assuming a conflict of interests between agents regarding their ideal actions. When players agree on the state-contingent profile of decisions,

\footnotetext{
${ }^{3}$ This extension has also been analyzed recently under cheap talk in Gordon (2010).

${ }^{4}$ They call it "single crossing" but it is weaker than the usual definition.

${ }^{5}$ Whether communication is private or public can make a difference on the set of possible equilibrium outcomes and on the existence of a fully revealing equilibrium, as shown in Farrell and Gibbons (1989) and Goltsman and Pavlov (2011) in a cheap talk framework, and in Koessler (2008) in an information disclosure framework.
} 
communication of dispersed private information is trivial and the questions raised emerge from physical restrictions on the communication rather than from strategic hindrances.

We consider quadratic payoff functions as in Morris and Shin $(2002,2007)$ and Cornand and Heinemann (2008) except that they assume that all the agents are symmetric: they have homogenous coordination motives and they want to adapt their individual decision to the same common state. Every player initially gets a private imperfect signal about that state as well as a public one. Their focus is on the trade-off between the relative precision of private signals and the common understanding provided by public ones, which matters for coordination. Angeletos and Pavan (2007) propose a more general framework which enables to link the substituability or complementarity of player's actions to the sensibility of their equilibrium decisions to either private or public signals. In the same coordination games, Hellwig and Veldkamp (2009) and Myatt and Wallace (2011) have recently endogenized the acquisition of information about the common state to match. The publicity of some signals therefore results from the agents' information search and depends on how complementary agents' actions are. Information about the common state is also dispersed in Calvó-Armengol and Martí $(2007,2009)$ but communication is restrained by the network in which the agents are embedded, which shapes equilibrium decisions. On the contrary, we assume there are no physical restrictions on who can speak to whom and let every agent communicate his private information with all the other ones.

When players's goals regarding ideal actions are not aligned, we ask whether it is yet possible to have voluntary revelation of information. Such a question has already been addressed in Alonso et al. (2008) and Rantakari (2008) who consider a cheap-talk communication stage preceding the decision stage. In their organizational context, each of the two divisions wants to adapt his decision to his private information only, and to the decision of the other. The need for coordination clearly improves direct communication between the two divisions, which is an effect present in Hagenbach and Koessler (2010) too. In the latter work, communication is also cheap-talk and heterogeneous players play a coordination game of incomplete information similar to the one considered here. However, the form of ideal actions is a particular case of the one considered in the present work, as it is given by the sum of binary private signals and a constant positive or negative bias. A full characterization of how the biases in the population shapes the communication occurring in equilibrium is provided. A closely related paper is Galeotti, Ghiglino, and Squintani (2011) who consider similar form for ideal actions but analyze cheap-talk communication about possibly correlated types, abstracting away from coordination motives.

Calvo-Armengol et al. (2011) analyze a setting where each player wants to adapt to a private state and to others' actions, with different intensities of interdependence of actions for different pairs of players. In their work, strategic choices do not concern messages sent, but formation of costly communication links. From the communication network formed, influences of players' private information on equilibrium actions are deduced for various patterns of interaction between actions. We also allow for such an heterogeneity in the weights players put on the need to coordinate with various agents, and show that these parameters can have an impact on certification requirements for full revelation to occur. 


\section{$3 \quad$ Model and Preliminary Result}

\subsection{Disclosure Game}

Let $N=\{1, \ldots, n\}$ be a finite set of players. Each player $i$ is privately informed about his type $s_{i} \in S_{i}$, where $S_{i}$ is a finite set $\left\{s_{i}^{1}, s_{i}^{2} \ldots\right\}$ whose elements are completely ordered as $s_{i}^{1}<s_{i}^{2}<\cdots$. Let $q \in \Delta(S)$ be the strictly positive prior probability distribution over the set of type profiles $S \equiv$ $\prod_{i} S_{i}$. After being informed about his own type each player $i$ chooses an action $a_{i} \in A_{i}$, and gets a payoff $u_{i}(a ; s)$, where $a=\left(a_{1}, \ldots, a_{n}\right) \in A \equiv \prod_{i} A_{i}$ is the action profile and $s=\left(s_{1}, \ldots, s_{n}\right) \in S$ is the type profile. We assume that for every $s \in S$, the (complete information) strategic form game $\left\langle N,\left(A_{i}\right)_{i \in N},\left(u_{i}(\cdot, s)\right)_{i \in N}\right\rangle$ has a unique Nash equilibrium, denoted by $\left(a_{i}^{*}(s)\right)_{i \in N} \in A .^{6}$

Before the Bayesian game $\left\langle N,\left(A_{i}\right)_{i \in N},\left(S_{i}\right)_{i \in N}, q,\left(u_{i}\right)_{i \in N}\right\rangle$ described below is played, but after each player has learnt his type, a (simultaneous) disclosure stage is introduced in which players can publicly and costlessly provide hard evidence about their types to the others. More precisely, every player $i$ sends a message $m_{i} \in M_{i}\left(s_{i}\right)$ to every other player, $M_{i}\left(s_{i}\right)$ denoting the (finite and nonempty) set of messages available to player $i$ when his type is $s_{i} \cdot{ }^{7}$ Let $M_{i}=\bigcup_{s_{i} \in S_{i}} M_{i}\left(s_{i}\right)$ be the set of all possible messages of player $i$. A message $m_{i} \in M_{i}$ sent by player $i$ provides hard evidence, or "certifies", to the receivers that player $i$ 's type is in $M_{i}^{-1}\left(m_{i}\right)$. For simplicity we assume that players always have the option to fully certify their type, meaning that for every player $i$ and every of his type $s_{i}$ there exists a message $m_{s_{i}} \in M_{i}\left(s_{i}\right)$ that only type $s_{i}$ can send: $M_{i}^{-1}\left(m_{s_{i}}\right)=\left\{s_{i}\right\}$. That is, every player $i$ can, whatever his type $s_{i}$, send a message certifying the singleton $\left\{s_{i}\right\}$. This assumption may be relaxed in special cases (see Section 5.4).

\subsection{A General Sufficient Condition for Full Disclosure}

In this section we provide general sufficient conditions for the existence of a fully revealing sequential equilibrium (i.e., a sequential equilibrium in which, along the equilibrium path, every player always learns the type profile before choosing his action) in the class of disclosure games described above. These fully revealing equilibria are constructed with disclosure strategies such that every player always fully certifies his type; that is, every player $i$, whatever his type $s_{i} \in S_{i}$, send a message $m_{s_{i}} \in M_{i}\left(s_{i}\right)$ such that $M_{i}^{-1}\left(m_{s_{i}}\right)=\left\{s_{i}\right\}$. For every player $i$ and message $m_{i} \in M_{i}$ off the equilibrium path, we then consider beliefs for the other players about player $i$ 's type that put probability one on a single feasible type in $M_{i}^{-1}\left(m_{i}\right)$. Said differently, when players other than $i$ observe a message sent by player $i$ certifying that player $i$ 's type is in a subset $S_{i}^{\prime}$ of $S_{i}$, they all believe that player $i$ is of one type in $S_{i}^{\prime}$ with probability one.

Assuming that the beliefs (along and off the equilibrium path) are common to all players other than $i$ (because messages are sent publicly) and only depend on player $i$ 's message (in particular, they do not depend on $m_{-i}$ and on the receivers' types), it is easy to check that strong belief consistency in the sense of Kreps and Wilson (1982) is satisfied. ${ }^{8}$ Sequential rationality in the

\footnotetext{
${ }^{6}$ When uniqueness is not satisfied any selection among the set of Nash equilibria can be done. The set of strategies could also be extended to mixed strategies if required.

${ }^{7}$ In cheap talk games, note that the sets $M_{i}\left(s_{i}\right)$ do not depend on $s_{i}$.

${ }^{8}$ Formally, to guarantee that every player $j \neq i$ assigns probability one to a single type $t_{i} \in M_{i}^{-1}\left(m_{i}\right)$ of player $i$ for a message $m_{i}$ off the equilibrium path from player $i$, it suffices to consider a perturbed and completely mixed strategy for player $i$ such that type $t_{i}$ sends message $m_{i}$ with probability $\varepsilon$ and all other types in $M_{i}^{-1}\left(m_{i}\right)$ send
} 
disclosure and action stages is defined as usual.

With such beliefs after the disclosure stage, every message $m_{i} \in M\left(s_{i}\right)$ of player $i$ leads to player $i$ being considered as a type in $M_{i}^{-1}\left(m_{i}\right)$, say $t_{i}$, by all the other players, who then take equilibrium actions $a_{-i}^{*}\left(t_{i}, s_{-i}\right)$. For two types $s_{i}$ and $t_{i}$ of player $i$ we say that type $s_{i}$ wants to imitate type $t_{i}$ if player $i$ of type $s_{i}$ is strictly better off when all the other players play the equilibrium actions (under complete information) as if they all believed that player $i$ 's type were $t_{i}$ instead of $s_{i}$ :

Definition 1 A type $s_{i}$ wants to imitate a type $t_{i}$ if we have:

$E_{s_{-i} \mid s_{i}}\left[u_{i}\left(a_{i}^{*}\left(s_{i}, s_{-i}\right), a_{-i}^{*}\left(s_{i}, s_{-i}\right) ; s_{i}, s_{-i}\right)\right]<E_{s_{-i} \mid s_{i}}\left[u_{i}\left(B R_{i}\left(a_{-i}^{*}\left(t_{i}, s_{-i}\right) ; s_{i}, s_{-i}\right), a_{-i}^{*}\left(t_{i}, s_{-i}\right) ; s_{i}, s_{-i}\right)\right]$.

Note that this definition of informational incentive compatibility is more complicated than the usual one used in mechanism design or sender-receiver games. Indeed, our definition takes into account, as in the definition of a communication equilibrium (Myerson, 1982, Forges, 1986), the best response of player $i$ of type $s_{i}$ to other players' (incorrect) beliefs $t_{i}$ denoted $B R_{i}\left(a_{-i}^{*}\left(t_{i}, s_{-i}\right) ; s_{i}, s_{-i}\right)$.

For a player $i$ and every of his available messages $m_{i}$, we construct a fully revealing equilibrium using beliefs after the disclosure game that put probability one on a type in $M_{i}^{-1}\left(m_{i}\right)$ called the worst-case type and defined as follows:

Definition 2 For every message $m_{i} \in M_{i}$ from player $i$, a worst-case type for the set $M_{i}^{-1}\left(m_{i}\right)$, denoted by $w c t^{i}\left(m_{i}\right) \in M_{i}^{-1}\left(m_{i}\right)$, is a type in $M_{i}^{-1}\left(m_{i}\right)$ that no other type in $M_{i}^{-1}\left(m_{i}\right)$ wants to imitate. That is, a worst-case type $w c t^{i}\left(m_{i}\right)$ for $M_{i}^{-1}\left(m_{i}\right)$ is such that, for all $s_{i} \in M_{i}^{-1}\left(m_{i}\right)$,

$$
\begin{aligned}
E_{s_{-i} \mid s_{i}} & {\left[u_{i}\left(a_{i}^{*}\left(s_{i}, s_{-i}\right), a_{-i}^{*}\left(s_{i}, s_{-i}\right) ; s_{i}, s_{-i}\right)\right] \geq } \\
& E_{s_{-i} \mid s_{i}}\left[u_{i}\left(B R_{i}\left(a_{-i}^{*}\left(w c t^{i}\left(m_{i}\right), s_{-i}\right) ; s_{i}, s_{-i}\right), a_{-i}^{*}\left(w c t^{i}\left(m_{i}\right), s_{-i}\right) ; s_{i}, s_{-i}\right)\right] .
\end{aligned}
$$

If it is possible to find a worst-case type for every subset of types of every player $i$, then no player $i$ of any type $s_{i} \in S_{i}$ has an interest in deviating from fully certifying his type (i.e., sending a message $m_{s_{i}} \in M_{i}\left(s_{i}\right)$ such that $\left.M_{i}^{-1}\left(m_{s_{i}}\right)=\left\{s_{i}\right\}\right)$ to sending any message $m_{i} \in M_{i}\left(s_{i}\right) .{ }^{9}$ We will show that under the two following conditions, for any player $i$ and any subset of his types $S_{i}^{\prime} \subseteq S_{i}$, there cannot be a "cycle of imitations" in $S_{i}^{\prime}$. This means that for any $S_{i}^{\prime} \subseteq S_{i}$ there is a type in $S_{i}^{\prime}$ that no other type in $S_{i}^{\prime}$ wants to imitate. Hence, for any message certifying that player $i$ 's type is in $S_{i}^{\prime}$, the type that no other type wants to imitate is a worst-case type for player $i$ in $S_{i}^{\prime}{ }^{10}$

Condition 1 (No Reciprocal Imitation) A Bayesian game satisfies No Reciprocal Imitation (NRI) if for every player $i$ and every pair of his types $s_{i}$ and $s_{i}^{\prime}$, we have: If type $s_{i}$ wants to imitate type $s_{i}^{\prime}$ then type $s_{i}^{\prime}$ does not want to imitate type $s_{i}$.

$\overline{m_{i}}$ with probability $\varepsilon^{2}$, with $\varepsilon>0$ and $\varepsilon \rightarrow 0$. This construction works even with correlated types as long as every profile of types has a strictly positive prior probability.

${ }^{9}$ The existence of worst-case types is sufficient for the existence of a fully revealing equilibrium, but may not be necessary; simple examples can be constructed where there is no worst-case type but non-degenerated beliefs off the equilibrium path can sustain full information disclosure.

${ }^{10}$ Since we have made no assumption on exactly which subsets of types $S_{i}^{\prime}$ a player $i$ can certify, we show the existence of a worst-case type for every subset of his types $S_{i}^{\prime}$. 
Condition 2 (Partially Transitive Imitation) A Bayesian game satisfies Partially Transitive Imitation (PTI) if for every player $i$ with at least three possible types and for every triple of his types such that $s_{i}^{\prime}<s_{i}, s_{i}^{\prime \prime}$ or $s_{i}^{\prime}>s_{i}, s_{i}^{\prime \prime}$ we have: If (i) type $s_{i}$ wants to imitate type $s_{i}^{\prime}$ and (ii) type $s_{i}^{\prime}$ wants to imitate type $s_{i}^{\prime \prime}$, then (iii) type $s_{i}$ wants to imitate type $s_{i}^{\prime \prime}$.

Under Condition PTI any cycle of imitations with strictly more than two types includes a smaller cycle. Indeed, consider a cycle of imitations for player $i$ containing at least three types such that $s_{i}^{\prime}$ is the smallest type in this cycle. Let $s_{i}>s_{i}^{\prime}$ be a type that wants to imitate $s_{i}^{\prime}$ in the cycle, and let $s_{i}^{\prime \prime}>s_{i}^{\prime}$ be a type that $s_{i}^{\prime}$ wants to imitate in the cycle. By PTI, $s_{i}$ also wants to imitate $s_{i}^{\prime \prime}$, so a smaller cycle is included in the previous one. By recurrence, if a cycle exists then it includes a cycle with only two types. It follows from Condition NRI that no cycle exists at all, so a worst-case type always exists. This proves the following lemma:

Lemma 1 Assume that conditions NRI and PTI are satisfied. Then, for every player $i$, every (non-empty) subset of types $S_{i}^{\prime} \subseteq S_{i}$ has a worst-case type. Hence, a fully revealing sequential equilibrium exists.

In most existing models of strategic information disclosure, condition NRI alone is sufficient for the existence of a worst-case type (see, for example, Proposition 3.1 in Giovannoni and Seidmann, 2007) because it is assumed that the sender's expected payoff is single-peaked with respect to the receiver's belief about the sender's type. ${ }^{11}$ In our class of coordination games below, it can be shown that if there are only two players, then each player's expected payoff is single-peaked with respect to the other player's belief, which fails to be true with three players or more.

\subsection{A Class of Coordination Games}

From now on we assume that when the type profile is $s=\left(s_{1}, \ldots, s_{n}\right) \in S$, player $i$ 's payoff function is given by

$$
u_{i}\left(a_{1}, \ldots, a_{n} ; s\right)=-\alpha_{i i}\left(a_{i}-\theta_{i}(s)\right)^{2}-\sum_{j \neq i} \alpha_{i j}\left(a_{i}-a_{j}\right)^{2},
$$

where $\alpha_{i j}>0$ for every $i, j \in N$. This utility function includes as particular cases most of the utility functions used in the models with strategic complementarities discussed in Section 2.2. In particular, it allows heterogeneous coordination motives $\left(\alpha_{i j}\right.$ could be different from $\alpha_{k l}$ for all pairs of players $(i, j)$ and $(k, l))$ and, more importantly, ideal actions $\theta_{i}(s)$ could differ across players and depend on all players' types. Normalizing players' utility functions we can assume without loss of generality that $\alpha_{i j} \in(0,1)$ and $\sum_{j \in N} \alpha_{i j}=1$. The first component of agent $i$ 's utility function is a quadratic loss increasing in the distance between his action $a_{i}$ and his ideal action $\theta_{i}(s) \in \mathbb{R} .{ }^{12}$ The second component is a miscoordination quadratic loss which increases in the distance between $i$ 's action and other agents' actions. The constant $\alpha_{i j} \in(0,1)$ weights agent $i$ 's coordination motives

\footnotetext{
${ }^{11}$ In that case, we have: if $s_{i}$ wants to imitate $s_{i}^{\prime}$, then $s_{i}$ also wants to imitate all the types $s_{i}^{\prime \prime}$ in between $s_{i}$ and $s_{i}^{\prime}$, that is, all the types $s_{i}^{\prime \prime}$ such that $s_{i}<s_{i}^{\prime \prime}<s_{i}^{\prime}$ or $s_{i}^{\prime}<s_{i}^{\prime \prime}<s_{i}$. From this observation, we can also deduce that any cycle of imitation involving at least three types must contain a smaller cycle. As before, the NRI assumption can then be used to conclude that no cycle exists at all.

${ }^{12}$ Notice that there is no loss of generality assuming that $\theta_{i}(s)$ is deterministic. If uncertainty is not fully resolved by conditioning on the type profile it suffices to replace every random ideal action by its expected value conditionally on $s$.
} 
with respect to $j$ 's action. Clearly, each player $i$ 's utility is not monotonic in others' actions: his utility is increasing with player $j$ 's action $a_{j}$ if $a_{i}>a_{j}$, and it is decreasing with $a_{j}$ if $a_{i}<a_{j}$.

The differences of the $\theta_{i}(s)$ across agents reflect agents' conflict of interests with respect to their ideal actions. If all $\theta_{i}(s)$ were equal for every type profile $s$, there would be no informational incentive problem and full information disclosure would therefore be trivially possible.

We make the following assumption throughout the paper. ${ }^{13}$

Assumption 1 For every $i, j \in N$ and $s_{-j} \in S_{-j}, \theta_{i}\left(s_{j}, s_{-j}\right)$ is weakly increasing in $s_{j}$.

Hence, a higher type for player $j$ induces a higher ideal action for every player. Notice that with private values (i.e., $\left.\theta_{i}(s)=\theta_{i}\left(s_{i}\right)\right)$ this assumption is automatically satisfied. This assumption is made in most sender-receiver games studied in the literature (e.g., Crawford and Sobel, 1982, Seidmann and Winter, 1997), where the ideal actions of the sender and the receiver are assumed to be increasing in the sender's type. Note that it does not prevent the sign of the difference between two players' ideal actions to change with the profile of types.

\subsection{Complete Information Equilibrium}

We characterize below players' best responses and equilibrium actions under complete information, i.e., when the profile of types $s \in S$ is commonly known. The utility of player $i$ can be rewritten as (minus a constant):

$$
u_{i}\left(a_{1}, \ldots, a_{n} ; s\right)=a_{i}\left[2 \alpha_{i i} \theta_{i}(s)+2 \sum_{j \neq i} \alpha_{i j} a_{j}-a_{i}\right]-\sum_{j \neq i} \alpha_{i j}\left(a_{j}\right)^{2} .
$$

Player $i$ 's best response to $a_{-i}$ is given by

$$
B R_{i}\left(a_{-i} ; s\right)=\alpha_{i i} \theta_{i}(s)+\sum_{j \neq i} \alpha_{i j} a_{j}
$$

Notice that player $i$ 's utility when he plays a best response is given by:

$$
u_{i}\left(a_{1}, \ldots, a_{n} ; s\right)=\left(a_{i}\right)^{2}-\sum_{j \neq i} \alpha_{i j}\left(a_{j}\right)^{2}, \quad \text { if } a_{i}=B R_{i}\left(a_{-i} ; s\right) .
$$

The system of equations formed by players' best responses can be written as:

$$
\underbrace{\left(\begin{array}{cccc}
1 & -\alpha_{12} & \cdots & -\alpha_{1 n} \\
-\alpha_{21} & \ddots & \ddots & \vdots \\
\vdots & -\alpha_{i j} & \ddots & \vdots \\
-\alpha_{n 1} & \cdots & \cdots & 1
\end{array}\right)}_{A}\left(\begin{array}{c}
a_{1} \\
\vdots \\
\vdots \\
a_{n}
\end{array}\right)=\left(\begin{array}{c}
\alpha_{11} \theta_{1}(s) \\
\vdots \\
\vdots \\
\alpha_{n n} \theta_{n}(s)
\end{array}\right) .
$$

\footnotetext{
${ }^{13}$ Example 2 in the next section shows that without this assumption a fully revealing equilibrium may fail to exist even when types are independently distributed.
} 
Denoting $B \equiv\left(\beta_{i j}\right)_{i j} \equiv A^{-1}$, every player's equilibrium action under complete information is given by the following linear combination of all the players' ideal actions:

$$
a_{i}^{*}(s)=\sum_{j \in N} \gamma_{i j} \theta_{j}(s)
$$

where $\gamma_{i j} \equiv \beta_{i j} \alpha_{j j} \in(0,1)$ for every $i, j \in N$, and $\sum_{j \in N} \gamma_{i j}=1 .{ }^{14}$ Notice that when coordination motives are symmetric (i.e., $\alpha_{i j}=\alpha$ for every $i \neq j$ ) we have $\gamma_{i j}=\frac{\alpha}{1+\alpha}, i \neq j$, and $\gamma_{i i}=\frac{1-(n-2) \alpha}{1+\alpha}$.

The following simple example uses the equilibrium characterization above to illustrate how to identify a worst-case type when there are only two possible type profiles.

Example 1 Assume that $n=2, \alpha_{i j}=1 / 2$ for every $i, j \in\{1,2\}, S_{1}=\{\underline{s}, \bar{s}\}$, and player 2 has no private information ( $S_{2}$ is a singleton). Player $i$ 's equilibrium action under complete information is

$$
a_{i}^{*}\left(s_{1}\right)=\frac{2 \theta_{i}\left(s_{1}\right)+\theta_{j}\left(s_{1}\right)}{3} .
$$

With $\left(\theta_{1}(\underline{s}), \theta_{2}(\underline{s})\right)=(0,1)$ and $\left(\theta_{1}(\bar{s}), \theta_{2}(\bar{s})\right)=(1,2)$ we get $\left(a_{1}^{*}(\underline{s}), a_{2}^{*}(\underline{s})\right)=\left(\frac{1}{3}, \frac{2}{3}\right)$ and $\left(a_{1}^{*}(\bar{s}), a_{2}^{*}(\bar{s})\right)$ $=\left(\frac{4}{3}, \frac{5}{3}\right)$. Here, player 1 of type $\bar{s}$ wants to imitate player 1 of type $\underline{s}$ because $a_{2}^{*}(\underline{s})=2 / 3$ is closer to his ideal action $\theta_{1}(\bar{s})=1$ than $a_{2}^{*}(\bar{s})=5 / 3$. On the contrary, type $\underline{s}$ does not want to imitate $\bar{s}$ because $a_{2}^{*}(\bar{s})=5 / 3$ is further away from his ideal action $\theta_{1}(\underline{s})=0$ than $a_{2}^{*}(\underline{s})=2 / 3$. Hence, $\bar{s}$ is a worst-case type of player 1 for $\{\underline{s}, \bar{s}\}$. Finally, note that the way types want to imitate each other in this example can be deduced simply from the fact that player 1 has a lower ideal action than player 2 whatever his type.

\section{Full Disclosure with Independent Types}

Our first result directly applies Lemma 1 to our coordination game in the case in which players' types are independently distributed:

Proposition 1 If players' types are independently distributed, then conditions NRI and PTI are satisfied, so a fully revealing sequential equilibrium exists.

Proof. See the appendix where we show that if players' types are independently distributed, then Conditions NRI and PTI are satisfied. Thus, by Lemma 1, a fully revealing sequential equilibrium exists.

The example below shows that if the ideal actions are not monotonic in types (i.e., Assumption 1 fails), then a fully revealing equilibrium may not exist, even with only two players and one-side incomplete information. The second 2-player example shows that a fully revealing equilibrium may also fail to exist when players' types are correlated.

\footnotetext{
${ }^{14}$ Each $\beta_{i j}$ is indeed positive because the matrix $B$ can be written as $B=(I d-\Omega)^{-1}=\sum_{k \geq 0} \Omega^{k}$, where all elements of $\Omega$ are in the interval $(0,1)$ and the sum over each line of $\Omega$ is smaller than 1 . When $\theta_{i}\left(s_{1}, \ldots, s_{n}\right)=\theta\left(s_{1}, \ldots, s_{n}\right)$ for every $i \in N$, every player's equilibrium action is obviously $a_{i}^{*}(s)=\theta(s)$; hence, $\sum_{j \in N} \gamma_{i j}=1\left(\left(\gamma_{i j}\right)_{i, j}\right.$ only depend on $\left(\alpha_{i j}\right)_{i, j}$, not on the form of players' values $\left.\left(\theta_{i}(\cdot)\right)_{i}\right)$.
} 
Example 2 (Non-monotonic ideal actions) Consider $n=2$ players, with symmetric weights on the quadratic losses, $\alpha_{i j}=1 / 2$ for every $i, j \in\{1,2\}$. Player 1 has two possible types, $S_{1}=\{\underline{s}, \bar{s}\}$, and player 2 has no private information. The ideal actions are given by $\theta_{1}(\underline{s})=\theta_{2}(\bar{s})=1$ and $\theta_{1}(\bar{s})=\theta_{2}(\underline{s})=0$, so Assumption 1 is not satisfied because players' ideal actions are not ordered in the same way with respect to player 1's type. If information is fully disclosed then the actions are given by the complete information equilibrium actions $a_{1}^{*}(\underline{s})=a_{2}^{*}(\bar{s})=2 / 3, a_{1}^{*}(\bar{s})=a_{2}^{*}(\underline{s})=1 / 3$. Intuitively, full disclosure is not feasible here because two types want to imitate each others ("no reciprocal imitation" fails): type $\underline{s}$ would like to imitate type $\bar{s}$ (to increase player 2 's action towards his ideal action $\theta_{1}(\underline{s})=1$ ), and type $\bar{s}$ would like to imitate type $\underline{s}$ (to decrease player 2's action towards his ideal action $\left.\theta_{1}(\bar{s})=0\right)$. To completely prove the non existence of a fully revealing equilibrium, let $\mu \in[0,1]$ be an arbitrary belief for player 2's about type $s_{1}=\underline{s}$ of player 1 after some message in $M_{1}(\underline{s}) \cap M_{1}(\bar{s}) \neq \emptyset$ sent by player 1 off the equilibrium path. After such a message, it is easy to show that players' actions are given by

$$
a_{1}\left(s_{1}\right)=\frac{2-\mu+3 \theta_{1}\left(s_{1}\right)}{6} \text { and } a_{2}=\frac{2-\mu}{3} .
$$

Player 1 does not deviate from full disclosure if whatever his type $s_{1} \in\{\underline{s}, \bar{s}\}$ we have:

$$
u_{1}\left(a_{1}^{*}\left(s_{1}\right), a_{2}^{*}\left(s_{1}\right) ; s_{1}\right) \geq u_{1}\left(a_{1}\left(s_{1}\right), a_{2} ; s_{1}\right),
$$

i.e., $-2 / 9 \geq-1 / 18(1+\mu)^{2}$ and $-2 / 9 \geq-1 / 18(2-\mu)^{2}$. The first condition, for type $\underline{s}$, implies $\mu=1$, and the second, for type $\bar{s}$, implies $\mu=0$, which is impossible. Hence, full disclosure is not a sequential equilibrium.

Example 3 (Correlated types) Consider again $n=2$ players, with $\alpha_{i j}=1 / 2$ for every $i, j \in$ $\{1,2\}$. Each player has two possible types, $S_{1}=\left\{\underline{s}_{1}, \bar{s}_{1}\right\}$ and $S_{2}=\left\{\underline{s}_{2}, \bar{s}_{2}\right\}$, with the (correlated) prior distribution $q\left(\underline{s}_{1}, \underline{s}_{2}\right)=q\left(\bar{s}_{1}, \bar{s}_{2}\right)=\frac{1-\varepsilon}{2}$ and $q\left(\underline{s}_{1}, \bar{s}_{2}\right)=q\left(\bar{s}_{1}, \underline{s}_{2}\right)=\frac{\varepsilon}{2}$, where $\varepsilon>0$ is small. Assume that the ideal action of player 1 is always zero: $\theta_{1}\left(s_{1}, s_{2}\right)=0$ for every $\left(s_{1}, s_{2}\right) \in S_{1} \times S_{2}$. If information is fully disclosed then the actions are given by the complete information equilibrium actions

$$
a_{1}^{*}\left(s_{1}, s_{2}\right)=\frac{\theta_{2}\left(s_{1}, s_{2}\right)}{3} \text { and } a_{2}^{*}\left(s_{1}, s_{2}\right)=\frac{2 \theta_{2}\left(s_{1}, s_{2}\right)}{3} .
$$

Let $\theta_{2}\left(\underline{s}_{1}, \bar{s}_{2}\right)=\theta_{2}\left(\bar{s}_{1}, \underline{s}_{2}\right)=0, \theta_{2}\left(\underline{s}_{1}, \underline{s}_{2}\right)=-1$ and $\theta_{2}\left(\bar{s}_{1}, \bar{s}_{2}\right)=1$ so that Assumption 1 is satisfied, but there is reciprocal imitation for $\varepsilon$ small enough. To show that there is no fully revealing equilibrium, consider a full disclosure strategy and let $\mu\left(s_{2}\right)$ be player 2's belief about type $\underline{s}_{1}$ for a message in $M_{1}\left(\underline{s}_{1}\right) \cap M_{1}\left(\bar{s}_{1}\right) \neq \emptyset$ sent off the equilibrium path when player 2's type is $s_{2} \in S_{2}$. After such a message, players' actions are given by

$$
a_{1}\left(s_{1}, s_{2}\right)=\frac{\mu\left(s_{2}\right) \theta_{2}\left(\underline{s}_{1}, s_{2}\right)+\left(1-\mu\left(s_{2}\right)\right) \theta_{2}\left(\bar{s}_{1}, s_{2}\right)}{3},
$$

and

$$
a_{2}\left(s_{2}\right)=\frac{2\left(\mu\left(s_{2}\right) \theta_{2}\left(\underline{s}_{1}, s_{2}\right)+\left(1-\mu\left(s_{2}\right)\right) \theta_{2}\left(\bar{s}_{1}, s_{2}\right)\right)}{3} .
$$


We obtain

$$
\begin{aligned}
& u_{1}\left(a_{1}^{*}\left(s_{1}, s_{2}\right), a_{2}^{*}\left(s_{1}, s_{2}\right) ; s_{1}, s_{2}\right)-u_{1}\left(a_{1}\left(s_{1}, s_{2}\right), a_{2}\left(s_{2}\right) ; s_{1}, s_{2}\right) \\
= & \left(\frac{\mu\left(s_{2}\right) \theta_{2}\left(\underline{s}_{1}, s_{2}\right)+\left(1-\mu\left(s_{2}\right)\right) \theta_{2}\left(\bar{s}_{1}, s_{2}\right)}{3}\right)^{2}-\left(\frac{\theta_{2}\left(s_{1}, s_{2}\right)}{3}\right)^{2}
\end{aligned}
$$

The expected value of this difference is positive for player 1 whatever his type if

$$
\begin{gathered}
(1-\varepsilon)\left[\left(\mu\left(\underline{s}_{2}\right)\right)^{2}-1\right]+\varepsilon\left(1-\mu\left(\bar{s}_{2}\right)\right)^{2} \geq 0, \\
(1-\varepsilon)\left[\left(1-\mu\left(\bar{s}_{2}\right)\right)^{2}-1\right]+\varepsilon\left(\mu\left(\underline{s}_{2}\right)\right)^{2} \geq 0 .
\end{gathered}
$$

Belief consistency requires that $\mu\left(\underline{s}_{2}\right) \geq 1-\varepsilon$ if and only if $\mu\left(\bar{s}_{2}\right) \geq \varepsilon$. Hence, the two inequalities above cannot be satisfied simultaneously when $\varepsilon$ is small enough, so a fully revealing sequential equilibrium does not exist.

\section{$5 \quad$ Full Disclosure with Constant Biases}

While most models in the literature on strategic communication assume that types are independently distributed (e.g., Okuno-Fujiwara et al., 1990, Van Zandt and Vives, 2007, Alonso et al., 2008, Rantakari, 2008), other standard information structures involve correlation of types, for example when players receive signals about a common parameter that are independently distributed conditionally on this parameter (types are therefore unconditionally correlated). In this section we extend the existence result of the previous section to any information structure with correlated types, assuming that players' ideal actions have a common value uncertainty component, and can be written as

$$
\theta_{i}\left(s_{1}, \ldots, s_{n}\right)=\theta\left(s_{1}, \ldots, s_{n}\right)+b_{i}, \quad \text { for every } i \in N,
$$

where $b_{i}$ is a constant "bias" parameter, and $\theta(s)$ is still assumed to be weakly increasing in $s$ (Assumption 1). ${ }^{15}$ Under this assumption, the equilibrium actions under complete information take the form

$$
a_{i}^{*}(s)=\sum_{j \in N} \gamma_{i j} \theta(s)+\sum_{j \in N} \gamma_{i j} b_{j}=\theta(s)+\sum_{j \in N} \gamma_{i j} b_{j} \equiv \theta(s)+B_{i}
$$

\section{$5.1 \quad$ Efficiency}

The next proposition shows that when the biases between players' ideal actions are constant across states, full information disclosure is always desirable for all players in the sense that it induces the best information structure in terms of equilibrium payoffs.

Proposition 2 With constant biases the equilibrium outcome under complete information ex-ante Pareto dominates the equilibrium outcome under any information structure.

Proof. See the appendix.

\footnotetext{
${ }^{15}$ The constant bias assumption is common in models studying communication in organizations (see, e.g., Dessein, 2002).
} 
The following example shows that this proposition is not necessarily true when biases are not constant.

Example 4 Consider a 2-player game with symmetric coordination motives $\left(\alpha_{12}=\alpha_{21}=\alpha\right)$ in which player 1 has no private information, $\theta_{1}(s)=0$ for every $s \in S=S_{2}$, and $E\left[\theta_{2}(s)\right]=0$. In this example we show that player 1 is strictly better off not knowing player 2's type when $\alpha$ is large enough. Under complete information, equilibrium actions are given by:

$$
a_{1}^{C I}(s)=\frac{\alpha \theta_{2}(s)}{1+\alpha} \quad \text { and } \quad a_{2}^{C I}(s)=\frac{\theta_{2}(s)}{1+\alpha}
$$

so player 1's utility under complete information is:

$$
u_{1}^{C I}(s)=-(1-\alpha)\left(\frac{\alpha \theta_{2}(s)}{1+\alpha}\right)^{2}-\alpha\left(\frac{(1-\alpha) \theta_{2}(s)}{1+\alpha}\right)^{2}=-\frac{(1-\alpha) \alpha}{(1+\alpha)^{2}}\left[\theta_{2}(s)\right]^{2}
$$

Under incomplete information, equilibrium actions are given by:

$$
a_{1}^{I I}(s)=0 \quad \text { and } \quad a_{2}^{I I}(s)=(1-\alpha) \theta_{2}(s),
$$

so player 1's utility under incomplete information is:

$$
u_{1}^{I I}(s)=-\alpha(1-\alpha)^{2}\left[\theta_{2}(s)\right]^{2} .
$$

Clearly, we have $u_{1}^{I I}(s)>u_{1}^{C I}(s)$ whenever $\theta_{2}(s) \neq 0$ when $\alpha$ is large enough. ${ }^{16}$

\subsection{An Ex-Post Fully Revealing Equilibrium}

To support full disclosure of information by every player $i$, we now explicitly find a worst-case type $t_{i} \in S_{i}^{\prime}$ for every $S_{i}^{\prime} \subseteq S_{i}$, such that, for all $s_{i} \in S_{i}^{\prime}$ and $s_{-i} \in S_{-i}$ we have:

$$
u_{i}\left(a_{i}^{*}\left(s_{i}, s_{-i}\right), a_{-i}^{*}\left(s_{i}, s_{-i}\right) ; s_{i}, s_{-i}\right) \geq u_{i}\left(B R_{i}\left(a_{-i}^{*}\left(t_{i}, s_{-i}\right) ; s_{i}, s_{-i}\right), a_{-i}^{*}\left(t_{i}, s_{-i}\right) ; s_{i}, s_{-i}\right) .
$$

For every player and every subset of his types, the worst-case type we identify depends on the parameters of the game. Precisely, the profile of biases $\left(b_{1}, \ldots, b_{n}\right)$ and the weights $\left(\alpha_{i j}\right)_{i, j}$ determine, for every $s$, whether a player $i$ 's equilibrium action $a_{i}^{*}(s)$ under complete information (given by Equation (7)) is relatively higher or lower than the ones of other players $j \neq i, a_{j}^{*}(s)$. In the case in which $X_{i} \equiv \sum_{j \neq i} \alpha_{i j}\left(B_{i}-B_{j}\right) \leq 0$, a worst-case type for any message $m_{i}$ sent by player $i$ corresponds to the highest type $s_{i}$ in the feasible subset of types $M_{i}^{-1}\left(m_{i}\right)$. The intuition, similar to the one of Example 1, ${ }^{17}$ is that, when $X_{i} \leq 0$, player $i$ would like to appear of a lower type than he is truly, while the reverse is not true. Therefore, players $j \neq i$ believing the highest type compatible with any message sent by player $i$ ensures he has no interest from deviating from full disclosure. On the contrary, in the case in which $X_{i} \equiv \sum_{j \neq i} \alpha_{i j}\left(B_{i}-B_{j}\right) \geq 0$, a worst-case

\footnotetext{
${ }^{16}$ When $\alpha>\frac{\sqrt{5}-1}{2} \simeq 0.62$.

${ }^{17}$ In Example 1 involving two agents only, the common value component is $\theta(\underline{s})=0$ and $\theta(\bar{s})=1$. Players' biases are given by $b_{1}=0$ and $b_{2}=1$. One can check easily that $X_{1} \leq 0$.
} 
type for any message $m_{i}$ sent by player $i$ corresponds to the lowest type $s_{i}$ in the feasible subset of types $M_{i}^{-1}\left(m_{i}\right)$. Constructing beliefs using such worst-case types, we show:

Proposition 3 With constant biases there exists a fully revealing sequential equilibrium in which every player's informational incentive constraints are satisfied ex-post, once he has learnt other players' types.

Proof. See the appendix.

We have identified a worst-case type for every player $i$ and every subset of his types $S_{i}^{\prime}$ no matter what the types $s_{-i}$ of the other players are. Full disclosure of information by player $i$ therefore can occur in equilibrium even if he knows the type of others, implying that the equilibrium is robust to the specification of players' prior beliefs about others' types. In particular, the existence of a fully revealing equilibrium applies even under correlated types, contrary to Proposition 1.

Finally note that in the particular case of symmetric coordination motive (i.e., $\alpha_{i j}=\alpha$ for every $i \neq j), X_{i}$ has the sign of $b_{i}-\sum_{j \neq i} b_{j} /(n-1) .{ }^{18}$ Hence, worst-case types for a player $i$ can be simply found by checking whether his bias is lower or higher than the average bias of the other players $\bar{b}=\sum_{j \neq i} b_{j} /(n-1)$, that is, by examining the relative position of their ideal actions: when his bias is lower than this average, players in $N \backslash\{i\}$ believe the highest type compatible with player $i$ 's report, and they believe the lowest type in the reverse case.

\subsection{Private Disclosure}

In the disclosure game that we have been considering, each player sends a public message about his type, in the sense that player $i$ sends the same message $m_{i}$ to every player $j \neq i$. In some situations, it is however the case that announcements cannot be made publicly, and that a different message could be sent by a player to every other one. In that case, a player $i$ of type $s_{i}$ can send a private message $m_{i}^{j} \in M_{i}\left(s_{i}\right)$ to every player $j \neq i$. Each player $j \neq i$ then makes a private inference from $i$ 's private message. ${ }^{19}$

Informational incentives constraints for player $i$ therefore require that he has no interest in deviating from sending a message fully certifying his type to any of the players $j \neq i$. To support full disclosure of information by a player $i$ whatever his prior beliefs about others' types, we consider beliefs for every player $j \neq i$ and message $m_{i}^{j}$ that assign probability one (i) on a single type $t_{i}^{j} \in M_{i}^{-1}\left(m_{i}^{j}\right)$ of player $i$, and (ii) on the fact that each other player $k(k \neq i, k \neq j)$ received a message certifying $t_{i}^{j}$ (so that player $j$ believes that player $k$ has the same belief about $i$ 's type as $j$ ). Formally, for every $j \neq i$ and for every $S_{i}^{j} \subseteq S_{i}$, we explicitly find a (worst-case) type $t_{i}^{j} \in S_{i}^{j}$, such that, for all $s_{i} \in S_{i}^{j}$ and $s_{-i} \in S_{-i}$ we have:

$$
u_{i}\left(a_{i}^{*}\left(s_{i}, s_{-i}\right), a_{-i}^{*}\left(s_{i}, s_{-i}\right) ; s_{i}, s_{-i}\right) \geq u_{i}\left(B R_{i}\left(\left(a_{j}^{*}\left(t_{i}^{j}, s_{-i}\right)\right)_{j \neq i} ; s_{i}, s_{-i}\right),\left(a_{j}^{*}\left(t_{i}^{j}, s_{-i}\right)\right)_{j \neq i} ; s_{i}, s_{-i}\right) .
$$

\footnotetext{
${ }^{18}$ For symmetric coordination motive, we have $B_{i}=\frac{1}{1+\alpha}\left[(1-(n-2) \alpha) b_{i}+\alpha \sum_{k \neq i} b_{k}\right]$ and therefore $B_{i}-B_{j}=$ $\frac{1}{1+\alpha}(1-(n-1) \alpha)\left(b_{i}-b_{j}\right)$. Noting that $\frac{\alpha}{1+\alpha}(1-(n-1) \alpha)>0$, we have that $\sum_{j \neq i} \alpha\left(B_{i}-B_{j}\right)$ has the sign of $(n-1) b_{i}-\sum_{j \neq i} b_{j}$.

${ }^{19}$ In particular, belief consistency of the sequential equilibrium does not prevent two players $j$ and $k$ receiving the same message $m_{i}^{j}=m_{i}^{k}$ off the equilibrium path to put probability one on different types $t_{i}^{j}$ and $t_{i}^{k}$ both belonging to $M_{i}^{-1}\left(m_{i}^{j}\right)=M_{i}^{-1}\left(m_{i}^{k}\right)$.
} 
The construction of beliefs after any private message is similar to the one used in the previous subsection for public messages. In the private disclosure game, when player $j$ receives a private message $m_{i}^{j}$ from player $i$ and his equilibrium action under complete information is relatively high compared to player $i$ 's one (i.e., $X_{i j}=B_{i}-B_{j} \leq 0$ ), he believes that player $i$ 's type is the highest type compatible with $i$ 's message and certified this type to all the other players. In the reverse case (i.e., $X_{i j} \geq 0$ ), he believes the lowest type compatible with $i$ 's message. Such a construction of beliefs enables to show:

Proposition 4 With constant biases the existence of a fully revealing sequential equilibrium extends to private disclosure.

Proof. See the appendix.

Again, note that when coordination motives are symmetric (i.e., $\alpha_{i j}=\alpha$ for every $i \neq j$ ), $X_{i j}$ has the sign of $b_{i}-b_{j}$. Hence, worst-case types for a player $i$ can be simply found by checking whether his bias is lower or higher than each player $j$ 's bias: when $b_{j} \geq b_{i}$, player $j \neq i$ believes the highest type compatible with player $i$ 's report, and he believes the lowest type in the reverse case.

\subsection{Partial Certifiability}

As shown in the proofs of Proposition 3 (public disclosure) and Proposition 4 (private disclosure), to support full disclosure of information, the form of players' beliefs off the equilibrium path depends on the parameters of the game (the profile of biases and the weights on coordination motives), on the player who deviates, and on the players who observe this deviation (which depends on whether the disclosure game is public or private). Our explicit finding of worst-case types for every player $i$ as a function of the relative positions of player $i$ 's equilibrium action under complete information with respect to other players' equilibrium actions (given by $X_{i} \equiv \sum_{i \neq j} \alpha_{i j}\left(B_{i}-B_{j}\right)$ under public disclosure and $X_{i j} \equiv B_{i}-B_{j}, j \neq i$, under private disclosure) has interesting implications on the certifiability requirements for full information disclosure. The next proposition shows how the assumption of full certifiability can be relaxed for cases in which the messages available for every type of every player have a special structure:

Proposition 5 (Fully disclosure with partial certifiability) In the public disclosure game, if each player $i$ such that $X_{i}<0$ can certify, whatever his type $s_{i}$, that his type is at most $s_{i}$ (i.e., there exists $m_{i} \in M_{i}\left(s_{i}\right)$ such that $\left.s_{i}=\max M_{i}^{-1}\left(m_{i}\right)\right)$, and each player $i$ such that $X_{i}>0$ can certify, whatever his type $s_{i}$, that his type is at least $s_{i}$ (i.e., there exists $m_{i} \in M_{i}\left(s_{i}\right)$ such that $\left.s_{i}=\min M_{i}^{-1}\left(m_{i}\right)\right)$, then there exists a fully revealing equilibrium.

In the private disclosure game, if each player $i$ such that $X_{i j} \leq 0$ for all $j \neq i$ can certify, whatever his type $s_{i}$, that his type is at most $s_{i}$, each player $i$ such that $X_{i j} \geq 0$ for all $j \neq i$ can certify, whatever his type $s_{i}$, that his type is at least $s_{i}$, and the other players can completely certify their types, then there exits a fully revealing equilibrium.

Proof. See the appendix.

In the previous subsections, we proved that, with completely certifiable types, a fully revealing equilibrium exists whatever the biases and the weights on coordination needs, both under public 
and private communication. On the contrary, the example below shows that, when types can only be partially certified, the possibility of full information disclosure depends on the communication protocol and on parameters of the game. In particular, it illustrates Proposition 5 by presenting a situation in which the certification possibilities lead to existence of a fully revealing equilibrium under public communication but not under private communication.

Example 5 Consider a game with $n=3$ players and symmetric coordination motives $\alpha_{i j}=\frac{1}{4}$ for every $i, j \in\{1,2,3\}, i \neq j$. Assume that only player 1 has private information $s \in\left\{s^{1}, s^{2}, s^{3}\right\}=$ $S_{1}=S$ with $s^{1}<s^{2}<s^{3}$. Let players' biases satisfy $b_{2} \leq b_{1} \leq b_{3}$ and $b_{1} \leq \frac{b_{2}+b_{3}}{2}$, and the messages available to player 1 be:

$$
M_{1}\left(s^{1}\right)=\left\{m^{1}, m^{2}, m^{3}\right\}, \quad M_{1}\left(s^{2}\right)=\left\{m^{2}, m^{3}\right\}, \quad M_{1}\left(s^{3}\right)=\left\{m^{3}\right\} .
$$

With such sets of available messages, each type $s$ of player 1 can certify that he is at most type $s^{x}$ by sending message $m^{x}$. Players' equilibrium actions under complete information are given by

$$
a_{i}(s)=\theta(s)+\frac{3 b_{i}+\sum_{j \neq i} b_{j}}{5},
$$

implying that $a_{2}(s)<a_{1}(s)<a_{3}(s)$ for every $s$.

By Proposition $5, b_{1} \leq \frac{b_{2}+b_{3}}{2}$ and the fact that player 1 can certify that he is at most any of his actual type imply the existence of a fully revealing equilibrium under public communication. Its construction relies on players 2 and 3 putting probability 1 on player 1 being of type $s^{x}$ when they receive message $m^{x}$, that is, believing the highest type in $M^{-1}\left(m^{x}\right)$. For example, such beliefs prevent player 1 of type $s^{2}$ to send publicly the message $m^{3}$ as he does not want to be considered as the player of a higher type $s^{3}$ by both the agents 2 and 3 .

However, $b_{2} \leq b_{1} \leq b_{3}$ and player 1 cannot fully certify all his types (in particular, he cannot fully certify $s^{2}$ and $s^{3}$ ) which means Proposition 5 does not apply under private communication. Consider the fully revealing disclosure strategy in the private disclosure game, where every type $s^{x}$ of player 1 sends message $m^{x}$. When player 1 's type is $s^{1}$ and player 1 deviates from sending $m^{1}$ to sending $m^{2}$ to player 2 (without deviating towards player 3 which is possible under private communication), his best response is to choose action $B R_{1}\left(a_{2}^{*}\left(s^{2}\right), a_{3}^{*}\left(s^{1}\right) ; s^{1}\right)=\frac{2\left(\theta\left(s^{1}\right)+b_{1}\right)+a_{2}^{*}\left(s^{2}\right)+a_{3}^{*}\left(s^{1}\right)}{4}=\frac{3 \theta\left(s^{1}\right)+\theta\left(s^{2}\right)}{4}+$ $\frac{3 b_{1}+b_{2}+b_{3}}{5}$. This deviation is profitable if we have:

$$
u_{1}\left(a^{*}\left(s^{1}\right), a_{2}^{*}\left(s^{1}\right), a_{3}^{*}\left(s^{1}\right) ; s^{1}\right)<u_{1}\left(B R_{1}\left(a_{2}^{*}\left(s^{2}\right), a_{3}^{*}\left(s^{1}\right) ; s^{1}\right), a_{2}^{*}\left(s^{2}\right), a_{3}^{*}\left(s^{1}\right) ; s^{1}\right) .
$$

After some simplifications, we get that player 1 deviates if:

$$
b_{1}-b_{2}>\frac{15\left(\theta\left(s_{2}\right)-\theta\left(s_{1}\right)\right)}{16} .
$$

Hence, under this condition there is no fully revealing equilibrium in the private disclosure game. The reason is that if player 2 believes that player 1 is of type $s^{x}$ when he gets a message $m^{x}$, then player 1 of type $s^{2}$ for instance has an interest in sending message $m^{3}$ instead of $m^{2}$ to player 2 only as $b_{2} \leq b_{1}$. 


\section{Conclusion}

The present paper contributes to the two strands of literature presented in Section 2, namely strategic information revelation and organizational economics, which have been recently connected through the introduction of divergence of interests between privately informed members of organizations. ${ }^{20}$ In such cases, agents differ in the ideal decision they would like the group members to coordinate on, and information revelation therefore entails a strategic aspect as players try to influence the others' actions by misrepresenting their private information. In this framework, we raise the question of whether voluntary and complete revelation of information can occur in equilibrium under the assumption that information is certifiable. We first provide sufficient conditions for the existence of a fully revealing equilibrium in general Bayesian games. Precisely, we show that a fully revealing sequential equilibrium exists in any incomplete information game exhibiting the two following properties : (i) there is no reciprocal imitation between any pair of types of any player, and (ii) for every player, imitations occurring for particular subsets of his types exhibit a transitivity property.

Next, we apply this general result to organizations where each member's motives are represented by quadratic cost functions trading off between taking an action close to an idiosyncratic ideal decision (function of all the private information), and taking it close to others' actions. Contrary to existing works examining strategic communication in a similar framework, we do not consider cheap-talk but study the incentives of players to disclosure their information when they all have the opportunity to fully certify their types. We show that a fully revealing sequential equilibrium exists if each player's ideal action is monotonic in types and types are independently distributed. We provide examples showing that full disclosure mail fail to occur when actions are non-monotonic or when types are correlated. With more structure on the ideal actions, namely assuming they are the sum of a common uncertain component and an individual bias constant across states, we prove the existence of a fully revealing equilibrium even when types are correlated, or when information can only be revealed privately. The complete information structure then Pareto-dominates any other information structure, which is wrong when the only assumption on ideal actions is monotonicity with respect to types. In that case, one ambitious goal would be to identify the ex-ante optimal information structure before asking whether it can emerge in equilibrium or not.

\section{A Appendix}

Proof of Proposition 1: Condition 1 (NRI). We first show that, if players's types are independently distributed, then Condition 1 (No Reciprocal Imitation) holds. To do so, we consider two types of player $i, s_{i}$ and $s_{i}^{\prime}$ with $s_{i}>s_{i}^{\prime}$, and show that the conditions that $s_{i}$ wants to imitate $s_{i}^{\prime}$ and $s_{i}^{\prime}$ wants to imitate $s_{i}$ cannot hold both at the same time. Using Definition $1, s_{i}$ wants to imitate $s_{i}^{\prime}$ if and only if:

$$
E_{s_{-i} \mid s_{i}} u_{i}\left[a_{i}^{*}\left(s_{i}, s_{-i}\right), a_{-i}^{*}\left(s_{i}, s_{-i}\right) ; s_{i}, s_{-i}\right]<E_{s_{-i} \mid s_{i}} u_{i}\left[B R_{i}\left(a_{-i}^{*}\left(s_{i}^{\prime}, s_{-i}\right) ; s_{i}, s_{-i}\right), a_{-i}^{*}\left(s_{i}^{\prime}, s_{-i}\right) ; s_{i}, s_{-i}\right] .
$$

\footnotetext{
${ }^{20}$ See, among others, Alonso et al. (2008), Rantakari (2008) or Hagenbach and Koessler (2010).
} 
To simplify the notations, let $s=\left(s_{i}, s_{-i}\right)$ and $s^{\prime}=\left(s_{i}^{\prime}, s_{-i}\right)$. Using Equation (4) to replace player $i$ 's utility when he plays a best response, we get:

$$
\begin{array}{ll} 
& E_{s_{-i} \mid s_{i}}\left[\left(a_{i}^{*}(s)\right)^{2}-\sum_{j \neq i} \alpha_{i j}\left(a_{j}^{*}(s)\right)^{2}\right]<E_{s_{-i} \mid s_{i}}\left[\left(B R_{i}\left(a_{j}^{*}\left(s^{\prime}\right)\right) ; s\right)^{2}-\sum_{j \neq i} \alpha_{i j}\left(a_{j}^{*}\left(s^{\prime}\right)\right)^{2}\right] \\
\Leftrightarrow \quad & E_{s_{-i} \mid s_{i}}\left[\left(a_{i}^{*}(s)-B R_{i}\left(a_{j}^{*}\left(s^{\prime}\right) ; s\right)\right)\left(a_{i}^{*}(s)+B R_{i}\left(a_{j}^{*}\left(s^{\prime}\right) ; s\right)\right)\right. \\
& \left.-\sum_{j \neq i} \alpha_{i j}\left(a_{j}^{*}(s)-a_{j}^{*}\left(s^{\prime}\right)\right)\left(a_{j}^{*}(s)+a_{j}^{*}\left(s^{\prime}\right)\right)\right]<0 .
\end{array}
$$

Given that $a_{i}^{*}(s)=B R_{i}\left(a_{i}^{*}(s) ; s\right)$, we have $a_{i}^{*}(s)-B R_{i}\left(a_{j}^{*}\left(s^{\prime}\right) ; s\right)=\sum_{j \neq i} \alpha_{i j}\left(a_{j}^{*}(s)-a_{j}^{*}\left(s^{\prime}\right)\right)$ and obtain:

$$
E_{s_{-i} \mid s_{i}}[\sum_{j \neq i} \alpha_{i j} \underbrace{\left(a_{j}^{*}(s)-a_{j}^{*}\left(s^{\prime}\right)\right)}_{D_{j}} \underbrace{\left(a_{i}^{*}(s)+B R_{i}\left(a_{j}^{*}\left(s^{\prime}\right) ; s\right)-a_{j}^{*}(s)-a_{j}^{*}\left(s^{\prime}\right)\right)}_{A_{j}}]<0 .
$$

With the same reasoning, we get that $s_{i}^{\prime}$ wants to imitate $s_{i}$ if and only if:

$$
-E_{s_{-i} \mid s_{i}^{\prime}}[\sum_{j \neq i} \alpha_{i j} \underbrace{\left(a_{j}^{*}(s)-a_{j}^{*}\left(s^{\prime}\right)\right)}_{D_{j}} \underbrace{\left(a_{i}^{*}\left(s^{\prime}\right)+B R_{i}\left(a_{j}^{*}(s) ; s^{\prime}\right)-a_{j}^{*}\left(s^{\prime}\right)-a_{j}^{*}(s)\right)}_{B_{j}}]<0 .
$$

Given that players' types are independent, the probability distribution over the profiles $s_{-i}$ is the same for player $i$ knowing his type is $s_{i}$ or $s_{i}^{\prime}$, and we write $E_{s_{-i} \mid s_{i}}=E_{s_{-i} \mid s_{i}^{\prime}}=E_{s_{-i}}$. Equation (8) becomes $E_{s_{-i}}\left[\sum_{j \neq i} \alpha_{i j} D_{j} A_{j}\right]<0$ and Equation (9) becomes $E_{s_{-i}}\left[\sum_{j \neq i} \alpha_{i j} D_{j} B_{j}\right]>0$. From Assumption 1 (monotonicity of ideal actions), Equation (5) and the fact that $\gamma_{i j}>0$ for every $i, j \in N$, we have that every player $j$ 's equilibrium action $a_{j}^{*}(s)$ is weakly increasing in $s_{i}$ for every $i, j \in N$. Since $s_{i}>s_{i}^{\prime}$, we deduce that $D_{j}>0$ for every $j \neq i$ and every $s_{-i}$. Finally, we compare $A_{j}$ to $B_{j}$ :

$$
\begin{aligned}
A_{j}-B_{j}= & a_{i}^{*}(s)-a_{i}^{*}\left(s^{\prime}\right)+B R_{i}\left(a_{j}^{*}\left(s^{\prime}\right) ; s\right)-B R_{i}\left(a_{j}^{*}(s) ; s^{\prime}\right) \\
= & \alpha_{i i} \theta_{i}(s)+\sum_{j \neq i} \alpha_{i j} a_{j}^{*}(s)-\alpha_{i i} \theta_{i}\left(s^{\prime}\right)-\sum_{j \neq i} \alpha_{i j} a_{j}^{*}\left(s^{\prime}\right) \\
& +\alpha_{i i} \theta_{i}(s)+\sum_{j \neq i} \alpha_{i j} a_{j}^{*}\left(s^{\prime}\right)-\alpha_{i i} \theta_{i}\left(s^{\prime}\right)-\sum_{j \neq i} \alpha_{i j} a_{j}^{*}(s) \\
= & 2 \alpha_{i i}\left(\theta_{i}(s)-\theta_{i}\left(s^{\prime}\right)\right) .
\end{aligned}
$$

Since $s_{i}>s_{i}^{\prime}$, it follows from Assumption 1 that $A_{j}>B_{j}$ for every $j \neq i$ and every $s_{-i}$. With $D_{j}>0$ and $A_{j}>B_{j}$, Equations (8) and (9) cannot hold at the same time. A similar reasoning brings the same conclusion for the case in which $s_{i}<s_{i}^{\prime}$.

Proof of Proposition 1: Condition 2 (PTI). We next show that, if players's types are independently distributed, then Condition 2 (Partially Transitive Imitation) holds. To do so, we consider three types of player $i, s_{i}, s_{i}^{\prime}$ and $s_{i}^{\prime \prime}$ such that $s_{i}^{\prime}<s_{i}, s_{i}^{\prime \prime}$, and show that when (i) $s_{i}$ wants to imitate $s_{i}^{\prime}$ and (ii) $s_{i}^{\prime}$ wants to imitate $s_{i}^{\prime \prime}$ then (iii) $s_{i}$ wants to imitate $s_{i}^{\prime \prime}$. Using the same reasoning as to get Equation (8), we get that the statements of imitation (i), (ii) and (iii) are respectively equivalent 
to the following three conditions, where $s=\left(s_{i}, s_{-i}\right), s^{\prime}=\left(s_{i}^{\prime}, s_{-i}\right)$ and $s^{\prime \prime}=\left(s_{i}^{\prime \prime}, s_{-i}\right)$.

(i) $E_{s_{-i} \mid s_{i}}[\underbrace{\sum_{j \neq i} \alpha_{i j}\left(a_{j}^{*}(s)-a_{j}^{*}\left(s^{\prime}\right)\right)\left(a_{i}^{*}(s)+B R_{i}\left(a_{j}^{*}\left(s^{\prime}\right) ; s\right)-a_{j}^{*}(s)-a_{j}^{*}\left(s^{\prime}\right)\right)}_{C(i)}]<0$;

(ii) $E_{s_{-i} \mid s_{i}^{\prime}}[\underbrace{\sum_{j \neq i} \alpha_{i j}\left(a_{j}^{*}\left(s^{\prime}\right)-a_{j}^{*}\left(s^{\prime \prime}\right)\right)\left(a_{i}^{*}\left(s^{\prime}\right)+B R_{i}\left(a_{j}^{*}\left(s^{\prime \prime}\right) ; s^{\prime}\right)-a_{j}^{*}\left(s^{\prime}\right)-a_{j}^{*}\left(s^{\prime \prime}\right)\right)}_{C(i i)}]<0$;

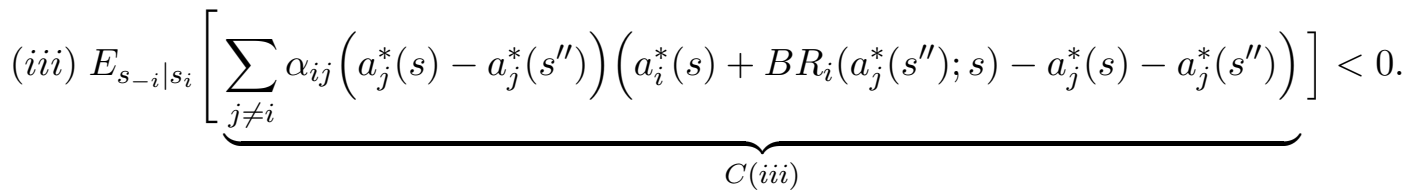

We show that $C(i i i)<C(i i)+C(i)$. We have:

$$
\begin{aligned}
& C(i i i)-C(i i)-C(i) \\
= & \sum_{j \neq i} \alpha_{i j}\left[\left(a_{j}^{*}(s)-a_{j}^{*}\left(s^{\prime \prime}\right)\right)\left(a_{i}^{*}(s)+B R_{i}\left(a_{j}^{*}\left(s^{\prime \prime}\right) ; s\right)-a_{j}^{*}(s)-a_{j}^{*}\left(s^{\prime \prime}\right)\right)\right. \\
& -\left(a_{j}^{*}\left(s^{\prime}\right)-a_{j}^{*}\left(s^{\prime \prime}\right)\right)\left(a_{i}^{*}\left(s^{\prime}\right)+B R_{i}\left(a_{j}^{*}\left(s^{\prime \prime}\right) ; s^{\prime}\right)-a_{j}^{*}\left(s^{\prime}\right)-a_{j}^{*}\left(s^{\prime \prime}\right)\right) \\
& \left.-\left(a_{j}^{*}(s)-a_{j}^{*}\left(s^{\prime}\right)\right)\left(a_{i}^{*}(s)+B R_{i}\left(a_{j}^{*}\left(s^{\prime}\right) ; s\right)-a_{j}^{*}(s)-a_{j}^{*}\left(s^{\prime}\right)\right)\right] \\
= & \sum_{j \neq i} \alpha_{i j}\left[\left(a_{j}^{*}(s)-a_{j}^{*}\left(s^{\prime \prime}\right)\right)\left(\alpha_{i i} \theta_{i}(s)+\sum_{j \neq i} \alpha_{i j} a_{j}^{*}(s)+\alpha_{i i} \theta_{i}(s)+\sum_{j \neq i} \alpha_{i j} a_{j}^{*}\left(s^{\prime \prime}\right)-a_{j}^{*}(s)-a_{j}^{*}\left(s^{\prime \prime}\right)\right)\right. \\
& -\left(a_{j}^{*}\left(s^{\prime}\right)-a_{j}^{*}\left(s^{\prime \prime}\right)\right)\left(\alpha_{i i} \theta_{i}\left(s^{\prime}\right)+\sum_{j \neq i} \alpha_{i j} a_{j}^{*}\left(s^{\prime}\right)+\alpha_{i i} \theta_{i}\left(s^{\prime}\right)+\sum_{j \neq i} \alpha_{i j} a_{j}^{*}\left(s^{\prime \prime}\right)-a_{j}^{*}\left(s^{\prime}\right)-a_{j}^{*}\left(s^{\prime \prime}\right)\right) \\
& \left.-\left(a_{j}^{*}(s)-a_{j}^{*}\left(s^{\prime}\right)\right)\left(\alpha_{i i} \theta_{i}(s)+\sum_{j \neq i} \alpha_{i j} a_{j}^{*}(s)+\alpha_{i i} \theta_{i}(s)+\sum_{j \neq i} \alpha_{i j} a_{j}^{*}\left(s^{\prime}\right)-a_{j}^{*}(s)-a_{j}^{*}\left(s^{\prime}\right)\right)\right] \\
= & 2 \alpha_{i i} \sum_{j \neq i} \alpha_{i j}\left[\left(\theta_{i}(s)-\theta_{i}\left(s^{\prime}\right)\right)\left(a_{j}^{*}\left(s^{\prime}\right)-a_{j}^{*}\left(s^{\prime \prime}\right)\right)\right]
\end{aligned}
$$

Since $s_{i}^{\prime}<s_{i}, s_{i}^{\prime \prime}$, it follows from Assumption 1 and from Equation (5) that $C(i i i)<C(i i)+$ $C(i)<0$ for every $s_{-i}$. Given that players' types are independent, the probability distribution over the profiles $s_{-i}$ is the same for player $i$ knowing his type is $s_{i}, s_{i}^{\prime}$ or $s_{i}^{\prime \prime}$. Hence, the statements of imitation (i) and (ii) imply statement (iii). A similar reasoning brings the same conclusion when $s_{i}^{\prime}>s_{i}, s_{i}^{\prime \prime}$.

Proof of Proposition 2. Thanks to the linearity of players' best reply we do not need to specify explicitly the information structure and associated equilibrium actions to prove this result. For any information structure it suffices to observe, using the same linear algebra as in Section 3.4, that the associated equilibrium action profile, denoted by the random variable $\left(\tilde{a}_{i}\right)_{i \in N}$ whose realizations depend on players' signal profile, has the same ex-ante expected value as under complete information:

$$
E\left[\tilde{a}_{i}\right]=E[\theta(s)]+B_{i}, \quad i \in N
$$


The resulting ex-ante equilibrium payoff of player $i$ is given by:

$$
\begin{aligned}
& E\left[-\alpha_{i i}\left(\tilde{a}_{i}-\theta(s)-b_{i}\right)^{2}-\sum_{j \neq i} \alpha_{i j}\left(\tilde{a}_{i}-\tilde{a}_{j}\right)^{2}\right] \\
& =-\alpha_{i i} \operatorname{Var}\left(\tilde{a}_{i}-\theta(s)-b_{i}\right)-\alpha_{i i}\left[E\left(\tilde{a}_{i}-\theta(s)-b_{i}\right)\right]^{2}-\sum_{j \neq i} \alpha_{i j} \operatorname{Var}\left(\tilde{a}_{i}-\tilde{a}_{j}\right)-\sum_{j \neq i} \alpha_{i j}\left[E\left(\tilde{a}_{i}-\tilde{a}_{j}\right)\right]^{2} \\
& =-\alpha_{i i} \operatorname{Var}\left(\tilde{a}_{i}-\theta(s)-b_{i}\right)-\sum_{j \neq i} \alpha_{i j} \operatorname{Var}\left(\tilde{a}_{i}-\tilde{a}_{j}\right)-\alpha_{i i}\left[B_{i}-b_{i}\right]^{2}-\sum_{j \neq i} \alpha_{i j}\left[B_{i}-B_{j}\right]^{2} .
\end{aligned}
$$

Under complete information about $s$ and constant biases we have $\tilde{a}_{i}-\tilde{a}_{j}=a_{i}^{*}(s)-a_{j}^{*}(s)=B_{i}-B_{j}$ and $\tilde{a}_{i}-\theta(s)-b_{i}=B_{i}-b_{i}$, so in that case the variances in the equation above are equal to zero. It follows that every player is strictly better off ex-ante under complete information about $s$ than under incomplete information.

Proof of Proposition 3. When types are fully certifiable, the simplest way to support a fully revealing equilibrium is to consider a disclosure strategy profile such that every player completely certifies his type to all the other players whatever his type. Consider a deviation by player $i$ from a fully revealing disclosure strategy to a message $m_{i} \in M_{i}\left(s_{i}\right)$ when his type is $s_{i}$. To prevent such a deviation it suffices to show that we can always find a worst-case type $t_{i} \in M_{i}^{-1}\left(m_{i}\right)$ that only depends on the identity of player $i$ and the message $m_{i}$ such that type $s_{i}$ of player $i$ does not want to imitate type $t_{i}$ whatever the realization of other players' types, $s_{-i}$ :

$$
u_{i}\left(a_{i}^{*}\left(s_{i}, s_{-i}\right), a_{-i}^{*}\left(s_{i}, s_{-i}\right) ; s_{i}, s_{-i}\right) \geq u_{i}\left(B R_{i}\left(a_{-i}^{*}\left(t_{i}, s_{-i}\right) ; s_{i}, s_{-i}\right), a_{-i}^{*}\left(t_{i}, s_{-i}\right) ; s_{i}, s_{-i}\right) .
$$

Satisfying this no imitation condition for every $s_{-i}$ implies it is satisfied in expectation for player $i$ over the profile $s_{-i}$ whatever player $i$ 's beliefs about others' types.

To simplify the notations, let $s=\left(s_{i}, s_{-i}\right)$ and $t=\left(t_{i}, s_{-i}\right)$. Using Equation (4) to replace player $i$ 's utility when he plays a best response, the previous inequality can be rewritten as:

$$
\left(a_{i}^{*}(s)\right)^{2}-\sum_{j \neq i} \alpha_{i j}\left(a_{j}^{*}(s)\right)^{2} \geq\left(B R_{i}\left(a_{-i}^{*}(t) ; s\right)\right)^{2}-\sum_{j \neq i} \alpha_{i j}\left(a_{j}^{*}(t)\right)^{2} .
$$

The form of player $i$ 's best response to the actions of the other players is given by Equation (3) and we use Equation (7) for the case of constant biases to get:

$$
B R_{i}\left(a_{-i}^{*}(t) ; s\right)=\alpha_{i i}\left(\theta(s)+b_{i}\right)+\sum_{j \neq i} \alpha_{i j} a_{j}^{*}(t)=\alpha_{i i}\left(\theta(s)+b_{i}\right)+\sum_{j \neq i} \alpha_{i j}\left(\theta(t)+B_{j}\right) .
$$

From the fact that $B_{i}=\alpha_{i i} b_{i}+\sum_{j \neq i} \alpha_{i j} B_{j},{ }^{21}$ we get

$$
B R_{i}\left(a_{-i}^{*}(t) ; s\right)=\alpha_{i i} \theta(s)+\left(1-\alpha_{i i}\right) \theta(t)+B_{i} .
$$

\footnotetext{
${ }^{21}$ From Equation (7), we know that $a_{i}^{*}(s)=\theta(s)+B_{i}$. From the expression of $B R_{i}\left(a_{-i}^{*}(t) ; s\right)$ that we just calculated, we deduce that $B_{i}=\alpha_{i i} b_{i}+\sum_{j \neq i} \alpha_{i j} B_{j}$ since $a_{i}^{*}(s)=B R_{i}\left(a_{-i}^{*}(s) ; s\right)$.
} 
We now insert this expression into Inequality (11) and use the notations $\theta=\theta(s)$ and $\tau=\theta(t)$ :

$$
\begin{array}{ccc} 
& \left(\theta+B_{i}\right)^{2}-\sum_{j \neq i} \alpha_{i j}\left(\theta+B_{j}\right)^{2} \geq\left(\alpha_{i i} \theta+\left(1-\alpha_{i i}\right) \tau+B_{i}\right)^{2}-\sum_{j \neq i} \alpha_{i j}\left(\tau+B_{j}\right)^{2} \\
\Leftrightarrow & \left.\left[\left(1-\alpha_{i i}\right)(\theta-\tau)\right]\left[\theta+\alpha_{i i} \theta+\left(1-\alpha_{i i}\right) \tau+2 B_{i}\right)\right]-\sum_{j \neq i} \alpha_{i j}\left[(\theta-\tau)\left(\theta+\tau+2 B_{j}\right)\right] \geq 0 \\
\Leftrightarrow & (\theta-\tau)\left[\left(1-\alpha_{i i}\right)\left(\theta+\alpha_{i i} \theta+\left(1-\alpha_{i i}\right) \tau+2 B_{i}\right)-\sum_{j \neq i} \alpha_{i j}\left(\theta+\tau+2 B_{j}\right)\right] \geq 0 \\
\Leftrightarrow & (\theta-\tau)\left[\left(1-\alpha_{i i}\right)\left(\theta+\alpha_{i i} \theta+\left(1-\alpha_{i i}\right) \tau+2 B_{i}\right)-\left(1-\alpha_{i i}\right)(\theta+\tau)-\sum_{j \neq i} \alpha_{i j} 2 B_{j}\right] \geq 0 \\
\Leftrightarrow & (\theta-\tau)[\alpha_{i i}\left(1-\alpha_{i i}\right)(\theta-\tau)+2 \underbrace{\sum_{j \neq i} \alpha_{i j}\left(B_{i}-B_{j}\right)}_{X_{i}}] \geq 0 .
\end{array}
$$

If $X_{i} \geq 0$, then this inequality is satisfied when $\theta=\theta\left(s_{i}, s_{-i}\right) \geq \tau=\theta\left(t_{i}, s_{-i}\right)$, that is, when $t_{i} \leq s_{i}$ as $\theta(\cdot)$ is weakly increasing. Therefore, for every message $m_{i}$, considering $t_{i}=\min M_{i}^{-1}\left(m_{i}\right)$ guarantees that the incentive compatibility condition (10) is satisfied for every type $s_{i} \in M_{i}\left(m_{i}\right)$ of player $i$. Using the same reasoning, $t_{i}=\max M_{i}^{-1}\left(m_{i}\right)$ guarantees the condition when $X_{i} \leq 0$.

Proof of Proposition 4. As in the proof of Proposition 3 consider a disclosure strategy profile such that every player completely certifies his type to all the other players whatever his type. Consider a deviation by player $i$ of type $s_{i}$ from such a fully revealing disclosure strategy to a message profile $\left(m_{i}^{j}\right)_{j \neq i}$, with $m_{i}^{j} \in M_{i}\left(s_{i}\right)$ for $j \neq i$. To prevent such a deviation it suffices to show that we can always find, for every player $j \neq i$, a worst-case type $t_{i}^{j} \in M_{i}^{-1}\left(m_{i}^{j}\right)$ that now depends not only on the identity of player $i$ and the message $m_{i}^{j}$, but also on the identity of player $j$, such that type $s_{i}$ of player $i$ is better off when all players believe that player $i$ 's type is $s_{i}$ than when each player $j \neq i$ believes that it is commonly known that player $i$ 's type is $t_{i}^{j} \in M_{i}^{-1}\left(m_{i}^{j}\right)$ (and therefore player $j$ will play action $a_{j}^{*}\left(t_{i}^{j}, s_{-i}\right)$ after message $m_{i}^{j}$ from player $i$ ). There is a subtlety here in the belief system off the equilibrium path that did not appear with public disclosure: we assume that player $j$, when receiving message $m_{i}^{j}$, believes that all players believe that $i$ 's type is $t_{i}^{j}$. This is implied by belief consistency under public communication (in which case we would have $t_{i}^{j}=t_{i}^{k}$ for $j, k \neq i$ ), but is not required under private communication. The precise underlying assumption on beliefs is that, when receiving message $m_{i}^{j}$, player $j$ believes that $i$ 's type is $t_{i}^{j}$ and player $i$ has sent his equilibrium message (i.e., has certified that his type is $t_{i}^{j}$ ) to all the other players (in particular, player $j$ does not necessarily believe that each other player $k \notin\{i, j\}$ has received the same message has him). It can be checked that this belief system is still strongly consistent. ${ }^{22}$

The ex-post incentive compatible condition for player $i$ can therefore be written as:

$$
u_{i}\left(a_{i}^{*}\left(s_{i}, s_{-i}\right), a_{-i}^{*}\left(s_{i}, s_{-i}\right) ; s_{i}, s_{-i}\right) \geq u_{i}\left(B R_{i}\left(\left(a_{j}^{*}\left(t_{i}^{j}, s_{-i}\right)\right)_{j \neq i} ; s_{i}, s_{-i}\right),\left(a_{j}^{*}\left(t_{i}^{j}, s_{-i}\right)\right)_{j \neq i} ; s_{i}, s_{-i}\right) .
$$

To simplify the notations, let $s=\left(s_{i}, s_{-i}\right)$ and $t^{j}=\left(t_{i}^{j}, s_{-i}\right)$. Using Equation (4) to replace player $i$ 's

\footnotetext{
${ }^{22}$ The corresponding perturbed strategies could be such that each player $i$, whatever his type $s_{i}$, is infinitely more likely to send one private message off the equilibrium path than to send more than one private message off the equilibrium path.
} 
utility when he plays a best response, the previous inequality can be rewritten as:

$$
\left(a_{i}^{*}(s)\right)^{2}-\sum_{j \neq i} \alpha_{i j}\left(a_{j}^{*}(s)\right)^{2} \geq\left(B R_{i}\left(\left(a_{j}^{*}\left(t^{j}\right)\right)_{j \neq i} ; s\right)^{2}-\sum_{j \neq i} \alpha_{i j}\left(a_{j}^{*}\left(t^{j}\right)\right)^{2} .\right.
$$

Player $i$ 's best response is given by Equation (3) and we use Equation (7) for the case of constant bias to get:

$$
B R_{i}\left(\left(a_{j}^{*}\left(t^{j}\right)\right)_{j \neq i} ; s\right)=\alpha_{i i}\left(\theta(s)+b_{i}\right)+\sum_{j \neq i} \alpha_{i j} a_{j}^{*}\left(t^{j}\right)=\alpha_{i i}\left(\theta(s)+b_{i}\right)+\sum_{j \neq i} \alpha_{i j}\left(\theta\left(t^{j}\right)+B_{j}\right) .
$$

From the fact that $B_{i}=\alpha_{i i} b_{i}+\sum_{j \neq i} \alpha_{i j} B_{j}$, we get:

$$
B R_{i}\left(\left(a_{j}^{*}\left(t^{j}\right)\right)_{j \neq i} ; s\right)=\alpha_{i i} \theta(s)+\sum_{j \neq i} \alpha_{i j} \theta\left(t^{j}\right)+B_{i}
$$

We now insert this expression in Condition (13) and use the notations $\theta=\theta(s)$ and $\tau^{j}=\theta\left(t^{j}\right)$ :

$$
\begin{array}{ccc} 
& \left(\theta+B_{i}\right)^{2}-\sum_{j \neq i} \alpha_{i j}\left(\theta+B_{j}\right)^{2} \geq\left(\alpha_{i i} \theta+\sum_{j \neq i} \alpha_{i j} \tau^{j}+B_{i}\right)^{2}-\sum_{j \neq i} \alpha_{i j}\left(\tau^{j}+B_{j}\right)^{2} \\
\Leftrightarrow & & {\left[\left(\theta-\alpha_{i i} \theta-\sum_{j \neq i} \alpha_{i j} \tau^{j}\right)\left(\theta+\alpha_{i i} \theta+\sum_{j \neq i} \alpha_{i j} \tau^{j}+2 B_{i}\right)\right]-\sum_{j \neq i} \alpha_{i j}\left[\left(\theta-\tau^{j}\right)\left(\theta+\tau^{j}+2 B_{j}\right)\right] \geq 0} \\
\Leftrightarrow & {\left[\sum_{j \neq i} \alpha_{i j}\left(\theta-\tau^{j}\right)\left(\left(1+\alpha_{i i}\right) \theta+\sum_{k \neq i} \alpha_{i k} \tau^{k}+2 B_{i}\right)\right]-\sum_{j \neq i} \alpha_{i j}\left[\left(\theta-\tau^{j}\right)\left(\theta+\tau^{j}+2 B_{j}\right)\right] \geq 0} \\
\Leftrightarrow & \sum_{j \neq i} \alpha_{i j}\left[\theta-\tau^{j}\right]\left[2\left(B_{i}-B_{j}\right)+\alpha_{i i} \theta+\sum_{k \neq i} \alpha_{i k} \tau^{k}-\tau^{j}\right] \geq 0 \\
\Leftrightarrow & \sum_{j \neq i} \alpha_{i j}\left[\theta-\tau^{j}\right]\left[2\left(B_{i}-B_{j}\right)+\left(\theta-\tau^{j}\right)+\sum_{k \neq i} \alpha_{i k}\left(\tau^{k}-\theta\right)\right] \geq 0 \\
\Leftrightarrow & 2 \sum_{j \neq i} \alpha_{i j}\left(\theta-\tau^{j}\right) \underbrace{\left(B_{i}-B_{j}\right)}_{X_{i j}}+\underbrace{\sum_{j \neq i} \alpha_{i j}\left(\theta-\tau^{j}\right)\left[\left(\theta-\tau^{j}\right)-\sum_{k \neq i} \alpha_{i k}\left(\theta-\tau^{k}\right)\right]}_{Z} \geq 0
\end{array}
$$

We have $Z>0$ because $Z$ can be rewritten as $\sum_{j \neq i} \alpha_{i j}\left(\theta-\tau^{j}\right)^{2}-\left(\sum_{j \neq i} \alpha_{i j}\left(\theta-\tau^{j}\right)\right)^{2}$. Hence, using the monotonicity of $\theta(\cdot)$, Condition (14) holds by letting $t_{i}^{j}=\min M_{i}^{-1}\left(m_{i}^{j}\right)$ when $X_{i j}>0$ and $t_{i}^{j}=\max M_{i}^{-1}\left(m_{i}^{j}\right)$ when $X_{i j}<0$.

Proof of Proposition 5. The proofs are exactly the same as the proofs of Propositions 3 and 4 except that, along the equilibrium path, instead of fully certifying their types, players use the following messages: (i) In the public disclosure game, each player $i$ such that $X_{i}<0$ sends, when his type is $s_{i}$, a message $m_{i} \in M_{i}\left(s_{i}\right)$ such that $s_{i}=\max M_{i}^{-1}\left(m_{i}\right)$, and each player $i$ such that $X_{i}>0$ sends, when his type is $s_{i}$, a message $m_{i} \in M_{i}\left(s_{i}\right)$ such that $s_{i}=\min M_{i}^{-1}\left(m_{i}\right)$. (ii) In the private disclosure game, each player $i$ such that $X_{i j} \leq 0$ for all $j \in N$ sends, when his type is $s_{i}$, a message $m_{i}^{j} \in M_{i}\left(s_{i}\right)$ such that $s_{i}=\min M_{i}^{-1}\left(m_{i}^{j}\right)$ to every other player $j$, each player $i$ such that $X_{i j} \geq 0$ for all $j \in N$ sends, when his type is $s_{i}$, a message $m_{i}^{j} \in M_{i}\left(s_{i}\right)$ such that $s_{i}=\min M_{i}^{-1}\left(m_{i}^{j}\right)$ to every other player $j$, and the others completely certify their types. 


\section{References}

Alonso, R., W. Dessein, And N. Matouschek (2008): "When Does Coordination Require Centralization?" American Economic Review, 98, 145-179.

Anderson, S. And R. Renault (2006): "Advertising Content," American Economic Review, 96, 93-113.

Angeletos, G.-M. And A. Pavan (2007): "Efficient Use of Information and Social Value of Information," Econometrica, 75, 1103-1142.

BoArd, O. (2009): "Competition and Disclosure," The Journal of Industrial Economics, 57, 197213.

Calvó-Armengol, A. And J. D. Martí (2007): "Communication Networks: Knowledge and Decisions," American Economic Review Papers and Proceedings, 97, 1-6.

(2009): "Information Gathering in Organizations: Equilibrium, Welfare and Optimal Network Structure," Journal of the European Economic Association, 7, 116-161.

Calvo-Armengol, A., J. De Martí, And A. Prat (2011): "Communication and Influence," mimeo.

Cornand, C. and F. Heinemann (2008): "Optimal Degree of Public Information Dissemination," The Economic Journal, 118, 718-742.

Crawford, V. P. And J. Sobel (1982): "Strategic Information Transmission," Econometrica, 50, 1431-1451.

Dessein, W. (2002): "Authority and Communication in Organizations," Review of Economic Studies, 69, 811-832.

Farrell, J. And R. Gibbons (1989): "Cheap Talk with Two Audiences," American Economic Review, 79, 1214-1223.

Forges, F. (1986): "An Approach to Communication Equilibria," Econometrica, 54, 1375-1385.

Galeotti, A., C. Ghiglino, And F. Squintani (2011): "Strategic Information Transmission in Networks," mimeo.

Giovannoni, F. And D. J. Seidmann (2007): "Secrecy, Two-Sided Bias and the Value of Evidence'," Games and Economic Behavior, 59, 296-315.

Goltsman, M. And G. Pavlov (2011): "How to Talk to Multiple Audiences," Games and Economic Behavior, 72, 100-122.

Gordon, S. (2010): "On Infinite Cheap Talk Equilibria," mimeo.

Grossman, S. J. (1981): "The Informational Role of Warranties and Private Disclosure about Product Quality," Journal of Law and Economics, 24, 461-483.

Hagenbach, J. And F. Koessler (2010): "Strategic Communication Networks," Review of Economic Studies, 77, 1072-1099. 
Hellwig, C. And L. Veldkamp (2009): "Knowing What Others Know: Coordination Motives in Information Acquisition," The Review of Economic Studies, 76, 223.

Johnson, J. P. And D. P. Myatt (2006): "On the Simple Economics of Advertising, Marketing, and Product Design," American Economic Review, 96, 756-784.

Koessler, F. (2008): "Lobbying with Two Audiences: Public vs Private Certification," Mathematical Social Sciences, 55, 305-314.

Koessler, F. and R. Renault (2011): "When Does a Firm Disclose Product Information?" mimeo.

Kreps, D. M. And R. Wilson (1982): "Sequential Equilibria," Econometrica, 50, 863-894.

Mathis, J. (2008): "Full Revelation of Information in Sender-Receiver Games of Persuasion," Journal of Economic Theory, 143, 571-584.

Milgrom, P. (1981): "Good News and Bad News: Representation Theorems and Applications," Bell Journal of Economics, 12, 380-391.

Morris, S. And H. S. Shin (2002): "Social Value of Public Information," American Economic Review, 92, 1521-1534.

(2007): "Optimal Communication," Journal of the European Economic Association Papers and Proceedings, 5, 594-602.

Myatt, D. And C. Wallace (2011): "Endogenous Information Acquisition in Coordination Games," Review of Economic Studies, forthcoming.

Myerson, R. B. (1982): "Optimal Coordination Mechanisms in Generalized Principal-Agent Problems," Journal of Mathematical Economics, 10, 67-81.

Okuno-Fujiwara, A., M. Postlewaite, And K. Suzumura (1990): "Strategic Information Revelation," Review of Economic Studies, 57, 25-47.

Rantakari, H. (2008): "Governing Adaptation," The Review of Economic Studies, 75, 1257.

Seidmann, D. J. and E. Winter (1997): "Strategic Information Transmission with Verifiable Messages," Econometrica, 65, 163-169.

Sun, M. J. (2011): "Disclosing Multiple Product Attributes," Journal of Economics and Management Strategy, 20, 195-224.

Van Zandt, T. And X. Vives (2007): "Monotone Equilibria in Bayesian Games of Strategic Complementarities," Journal of Economic Theory, 134, 339-360. 